\section{Role of drug effects and UCS intensity in avoidance acquisition of the Maudsley MNR} and MR strains

LOUIS K. MARTIN and BARBARA J. POWELL, ${ }^{1}$ Galesburg State Research Hospital, Galesburg, Ill. 61401

The effects of psychoactive drugs on avoidance performance seem to depend upon emotionality level. The present study was aimed at determining whether or not this interactive effect would be manifested over a wide range of shock intensities. Findings were essentially negative, possibly due to the relatively high performance level of high-emotional $S$ s under placebo conditions.

Previous findings indicated that dosages of amobarbital up to $30 \mathrm{mg} / \mathrm{kg}$ improve escape-avoidance acquisition in rats (Kamano, Martin, \& Powell, 1966). However, this generalization had to be qualified in light of further data showing that the acquisition performance of Wistar rats classified as high emotionals improved as the drug dosage increased, while that of the low emotionals declined slightly (Martin, Powell, \& Kamano, 1966). Broadhurst (1964) has reported almost identical results with the Maudsley strains, using reserpine.

Despite the consistency of results pointing to a drugemotionality interaction (Broadhurst, 1964; Powell, 1967; Powell, Martin, \& Kamano, 1967), the importance or generality of this phenomenon is in doubt since, in the studies cited, shock intensity during training was restricted to moderate levels. While the interaction effect may be independent of shock intensity, there is some evidence to suggest that at least one of the interacting variables (drug effects) also interacts with shock intensity (Martin, Powell, \& Kamano, 1967).

Therefore, the purpose of this study is to determine whether or not the drugemotionality interaction is restricted to a limited range of shock intensities, by studying the effects of amobarbital sodium on the acquisition of escape avoidance under differing shock intensities using the Maudsley Reactive and Nonreactive strains (rats bred for differences in emotionality). SUBJECTS

The Ss, 75-day-old male Maudsley rats, included 64 from the MR strain and 64 from the MNR strain. They were bred and reared under controlled conditions (temperature maintained at $72 \operatorname{deg} \mathrm{F}$, relative humidity at $40 \%$, and lighting on a 12-h on-off schedule) at the Psychology Laboratory, Western Illinois University. Litters were handled at 1 day of age and then remained undisturbed. Maternity cages were fitted with an external food hopper, and shavings were unchanged from parturition to weaning. At 21 days, Ss were weaned, sexed, and placed in colony cages, separated by litters, strain, and sex. At 30-50 days of age, Ss were transported to the Psychology Laboratory, Galesburg State Research Hospital, where they remained unhandled until testing.

\section{APPARATUS}

Both the open-field and the avoidance apparatus (a Miller-Mowrer two-chamber shuttlebox) are fully described elsewhere (Powell, Martin, \& Kamano, 1967; and Powell, Martin, \& Kamano, 1965, respectively).

\section{PROCEDURE}

Prior to avoidance conditioning, Ss were tested in the open field for one 2-min session on 4 consecutive days. Note was made of ambulations (number of squares entered with all four feet) and defecations.

After open-field testing, Ss within each strain were assigned randomly to either drug or placebo conditions and to one of four shock intensities $(50,300,800$, or 1,500 microamperes) for avoidance training $(\mathrm{N}=8$ /group). Twenty minutes prior to each conditioning session, Ss received IP injections of $30 \mathrm{mg} / \mathrm{kg}$ amobarbital sodium (in normal saline) or placebo (normal saline equivalent to $2 \mathrm{cc} / \mathrm{kg}$ of body weight).

The Ss were given 20 trials per day for 4 consecutive days in the jump-box avoidance apparatus. Each trial consisted of CS onset followed $5 \mathrm{sec}$ later by US onset. Both CS and US remained on until S crossed the hurdle or for a maximum of $10 \mathrm{sec}$ of shock. Crossing the barrier during the 5-sec CS-US interval constituted a CAR. The intertrial interval varied randomly within a range of $2040 \mathrm{sec}$ (mean $=30 \mathrm{sec})$. In addition to CARs, intertrial hurdle crossings (IHCs) and ratings of freezing activity in the $2 \mathrm{sec}$ preceding each CS presentation were recorded (see Krieckhaus et al, 1965, for a description of the rating scale).

\section{RESULTS AND DISCUSSION}

As expected, open-field defecation scores in the two strains were quite different. Only two of the MNR Ss had scores above 0 , while those from MR Ss ranged from 4 to 26 . This result provided assurance that the breeding and rearing conditions to which these strains were submitted were sufficient to maintain the genotypic differences in emotionality.

The means for the three avoidance-conditioning measures involving CARs, IHCs, and freezing scores are presented in Table 1. The data were analyzed by separate 2 by 2 by 4 analyses of variance (Winer, 1962), the results of which are summarized in Table 2 in the form of $F$ values.

Dealing first with CARs, both the strain and shock-intensity variables generated statistically significant main effects. Strain differences were due to more avoidance responses from the MNRs than from the MRs. The main effect of shock intensity as determined by Duncan multiple-range tests was due to fewer CARs being emitted at

Table 1

Mean Scores During Avoidance Acquisition for Drug and Placebo Groups at Different Shock Intensities

\begin{tabular}{|c|c|c|c|c|c|}
\hline \multirow[b]{2}{*}{ Measure } & \multirow{2}{*}{$\begin{array}{c}\text { Shock } \\
\text { Intensity } \\
\mu_{\mathrm{a}}\end{array}$} & \multicolumn{2}{|c|}{ MR Strain } & \multicolumn{2}{|c|}{ MNR Strain } \\
\hline & & Drug & Placebo & Drug & Placebo \\
\hline \multirow[t]{2}{*}{ CARs } & $\begin{array}{r}50 \\
300 \\
800 \\
1500\end{array}$ & $\begin{array}{l}40 \\
45 \\
49 \\
31\end{array}$ & $\begin{array}{l}55 \\
43 \\
39 \\
32\end{array}$ & $\begin{array}{l}57 \\
53 \\
45 \\
47\end{array}$ & $\begin{array}{l}61 \\
53 \\
48 \\
45\end{array}$ \\
\hline & Total & 165 & 169 & 202 & 207 \\
\hline \multirow[t]{2}{*}{ IHCs } & $\begin{array}{r}50 \\
300 \\
800 \\
1500\end{array}$ & $\begin{array}{r}5 \\
21 \\
21 \\
12\end{array}$ & $\begin{array}{l}3 \\
7 \\
9 \\
4\end{array}$ & $\begin{array}{l}68 \\
48 \\
50 \\
55\end{array}$ & $\begin{array}{l}28 \\
16 \\
12 \\
19\end{array}$ \\
\hline & Total & 59 & 23 & 221 & 75 \\
\hline \multirow[t]{2}{*}{ Freezing } & $\begin{array}{r}50 \\
300 \\
800 \\
1500\end{array}$ & $\begin{array}{l}3.65 \\
3.72 \\
3.67 \\
3.74\end{array}$ & $\begin{array}{l}3.37 \\
3.60 \\
3.62 \\
3.59\end{array}$ & $\begin{array}{l}2.83 \\
3.07 \\
3.06 \\
3.23\end{array}$ & $\begin{array}{l}3.24 \\
3.35 \\
3.34 \\
3.35\end{array}$ \\
\hline & Total & 14.78 & 14.18 & 12.19 & 13.28 \\
\hline
\end{tabular}


Table 2

F Values Derived from Analyses of Variance of Avoidance Acquisition Measures

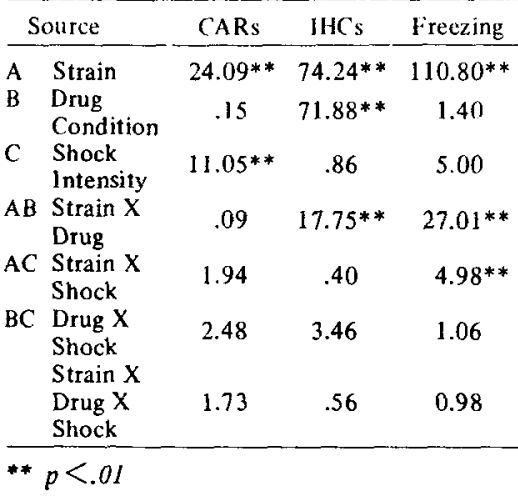

the highest 1,500-microampere intensity than at the 50,300 , or 800 levels $(\mathrm{p}<.01)$.

Significant interaction effects were found for both intertrial hurdle crossings (IHCs) and freezing behavior. Analysis of the simple main effects of the Drug by Strain interaction for IHCs indicated no differential effects on the strains while under drug, but under placebo, MRs had more IHCs than MNRs ( $F=4.21, p<.01)$. While drug condition did not affect the number of IHCs emitted by the MNRs, the MRs gave more IHCs under placebo than under amobarbital $(\mathrm{F}=5.60, \mathrm{p}<.01)$.

In freezing behavior, the Drug by Strain interaction was due to less freezing in the MNRs in the drug as compared to the placebo condition, while MRs actually showed more freezing under the drug. The Strain by Shock Intensity interaction for freezing was due to greater freezing by the MNRs at the three higher intensities than at the lowest, while there was no difference in freezing scores for the MRs over the various intensities.

While amobarbital had no demonstrable effect on CAR scores, it was effective in increasing IHCs and in attenuating freezing behavior in the MNR strain. The failure of amobarbital to increase general activity and lower freezing in the more emotional MR strain was a surprising result and is inconsistent with our previous findings, i.e., that use of amobarbital with Wistar rats selected as "high" emotionals increased both avoidance responses and hurdle crossings while decreasing freezing. In the present study, freezing of the more highly emotional strain actually tended to increase with amobarbital.

At this point, speculation as to why amobarbital failed to have an effect seems warranted. This drug appears to enhance avoidance performance only in those Ss giving a relatively low number of CARs under placebo. In comparison to other experimental populations termed "high emotional" and tested for differential drug effects in our laboratory (high-emotional Wistars, Tryon S1s), the MRs are relatively proficient avoiders. It may be that the drug did not affect MR avoidances simply because they did not "need" the drug since they were already performing at their optimal levels.

In summary, although amobarbital did alter some aspects of behavior of the Maudsley strains differentially during avoidance conditioning, the results were not in the direction anticipated on the basis of past findings.

\section{REFERENCES}

BROADHURST, P. L. The hereditary base for the action of drugs on animal behavior. In $\mathrm{H}$. Steinberg (Ed.), Animal behavior and druo action. Boston: Little, Brown, 1964. Pp. 224-237.

KAMANO, D. K., MARTIN, L. K., \& POWELL. B. J. Avoidance response acquisition and am oba r bital dosage levels. Psychopharmacologia, 1966, 8, 319-323.

KRIECKHAUS, E. E., MILLER, N. E., \& ZIMMERMAN, P. Reduction of freezing behavior and improvement of shock avoidance by d-amphetaminc. Journal of Comparative \& Physiological Psychology, 1965, 60, 36-40.

MARTIN, L. K., POWLLL, B. J., \& KAMANO, D. K. Effects of amobarbital sodium on avoidance performances of rats differing in emotionality. Proceedings of the 74th Annual Convention of the American Psychological Association, 1966, 125-126.

MARTIN, L. K., POWELL, B. J., \& KAMANO, $D$. K. Mediation of shock and drug-produced effects on avoidance responding. Psychonomic Science, 1967, 9, 3-4.

POWELL, B. J. Prediction of drug action: Elimination of error through emotionality. Proceedings of the 75 th Annual Convention of the American Psychological Association, 1967, 69-70.

POWELL, B. J., MARTIN, L. K., \& KAMANO, D. K. Effects of amobarbital sodium and meprobamate on acquisition of conditioned avoidance. Psychological Reports, 1965, 17, 691-694.

POWELL, B. J., MARTIN, L. K., \& KAMANO, D. K. Relationship between emotionality, drug effects, and avoidance responses in Tryon $S_{1}$ and $S_{3}$ strains. Canadian Journal of Psychology, 1967, 21, 294-300.

WINER, B. 1. Statistical principles in experimental design. New York; McGraw-Hill, 1962.

\section{NOTE}

1. Now at Washington University and Malcolm Bliss Mental Health Center, St. Louis, Missouri.

\section{Aspects of deprivation and allowance for grow th in young rats}

\section{MAXWELL TAYLOR, University Liverpool, Liverpool, England}

A replication of earlier work on the straight-line log-reciprocal growth function is reported. Negative results were achieved when the line of best fit, derived from an earlier log-reciprocal growth function in the same rat, was used to predict subsequent allowance for growth in deprivation and recovery of weight after deprivation.

Techniques for controlling deprivation in rats can be broadly classified into two categories: systematic restriction of access to food for some specified period or reduction to some percentage of free-feeding weight, and maintaining the rat at that weight, within certain arbitrarily defined limits. Difficulties arise, however, when either of the above procedures are applied to young, growing rats, where some allowance for growth is necessary if the relationship between deprived weight and free-feeding weight is to be in some sense constant.

Systematic restriction of access to food superficially appears to overcome the above difficulty in that within the access-to-food time limit, any amount of food may be consumed, but the procedire in general suffers from several severe difficulties (Bolles, 1967; Kaplan et al, 1956), and in terms of control of body weight, the above technique is preferable.

Defining deprivation in terms of percentage body weight appears to be satisfactory for adult rats, but no clear procedure exists for calculating the necessary allowance for growth in young rats. There have been two general approaches to this problem: either an increment, taking growth into account, may be added to the initial percentage weight (Pierrel, 1958) or the potential free-feeding weight, making the necessary allowance for growth, may be calculated, and the necessary adjustment then made in the percentage body weight (Kaplan et al, 